\title{
Reflections on the Ecolab and the Zone of Proximal Development
}

\author{
Rosemary Luckin ${ }^{1} \cdot$ Benedict du Boulay $^{2}$
}

Published online: 17 November 2015

(C) International Artificial Intelligence in Education Society 2015

\begin{abstract}
In 1999 we reported a study that explored the way that Vygotsky's Zone of Proximal Development could be used to inform the design of an Interactive Learning Environment called the Ecolab. Two aspects of this work have subsequently been used for further research. Firstly, there is the interpretation of the ZPD and its associated theory that was used to operationalize the ZPD so that it could be implemented in software. This interpretation has informed further research about how one can model context and its impact on learning, which has produced a design framework that has been successfully applied across a range of educational settings. Secondly, there is the Ecolab software itself. The software has been adapted into a variety of versions that have supported explorations into how to scaffold learners' metacognition, how to scaffold learners' motivation and the implications of a learner's goal orientation upon their use of the software. The findings from these studies have informed our understanding of learner scaffolding and have produced consistent results to demonstrate the importance of providing learners with appropriately challenging tasks and flexible support. Vygotsky's work is as relevant now as it was in 1999: it still has an important role to play in the development of educational software.
\end{abstract}

Keywords Vygotsky·Zone of Proximal Development (ZPD) - Interactive Learning Environment (ILE)

\section{Motivation}

The work reported in our 1999 paper (Luckin and du Boulay 1999) was motivated by a desire to understand more about how Vygotsky's Zone of Proximal Development

Rosemary Luckin

r.luckin@ioe.ac.uk

1 London Knowledge Lab, UCL Institute of Education, London, UK

2 The Human Centred Technology Group, University of Sussex, Brighton, UK 
(ZPD) (Vygotsky 1978, 1986) could be used to inform the design of educational technology. The ZPD was defined by Vygotsky as:

The discrepancy between a child's actual mental age and the level he reaches in solving problems with assistance indicates the zone of his proximal Development; ... Experience has shown that the child with the larger zone of proximal development will do much better in school.

(Vygotsky 1986: 187)

In order to explore the use of the ZPD in software design an Interactive Learning Environment (ILE) called the Ecolab was built and evaluated. Vygotsky's original presentation of the ZPD left several questions unanswered: the nature of the assistance that should be offered to learners and the timing of help interventions, for example. Our work was therefore also motivated by a desire to interpret the ZPD in a way that answered some of these questions.

The setting for the work we discuss was the school classroom and in particular learners between 8 and 10 years of age. This age group was selected because it was in line with Vygotsky's writing about the ZPD. At the time of writing the 1999 paper few schools were linked to the internet and not every classroom had a computer. The computers that were in schools were generally quite bulky PCs and there were no smart phones or small personal devices. Our operationalization of the ZPD was therefore developed to encompass the relatively limited technologies that were available at that time. The situation is different now, with most learners having internet access and some smart personal technology. The way that our ideas have developed takes into account these changes. In 1999 UK children were subjected to a national curriculum and to national testing. The curriculum implemented in the Ecolab therefore needed to encompass concepts found in the national curriculum. It focused upon a part of the science curriculum and in particular upon food webs and food chains. This situation has changed very little, there is still a great emphasis upon a national curriculum and national testing in the UK. In many other countries the situation is little different, for example in the US there are the U.S. Next Generation Science Standards and each year more countries join the OECD PISA evaluation tests. The work discussed in this paper continues with Vygotsky's desire to move away from such summative assessment of a child's independent ability towards an evaluation of their collaborative capability.

The Ecolab software was a tool to explore how well our interpretation of the ZPD supported learners. It offered learners a simulated environment that they could explore in order to complete a series of activities. Simulated environments for learning science, such as ecology, continue to be successful. For example, Dede and his colleagues at the Harvard Graduate School of Education have developed and studied the EcoMUVE curriculum (Dede et al. 2012, http://ecomuve.gse.harvard.edu). This offers middle school students two immersive, simulated ecosystems in which to learn science concepts and authentic inquiry practices. Learners can see plants and animals in their natural habitats, and collect data. They are set a problem to solve that requires them to work together, collecting and analyzing data. EcoMUVE supports learners through powerful visualisations and realistic data. Other systems that have focused on simulation include the games River City (http://muve.gse.harvard.edu/rivercityproject/ index.html) and Quest Atlantis (http://atlantisremixed.org). These have shown that 
immersive game-based learning environments can motivate and engage learners as well as providing a powerful new form of curriculum for teaching and learning science. In addition to systems that, like Ecolab, use simulation to support learning there have been a range of approaches to providing learners with timely assistance. For example, David Wood's Quadratic system (Wood and Wood 1999) embodies a contingent approach to providing help, MetaTutor (Azevedo et al. 2009) offers metacognitive support and the cognitive tutors (Koedinger et al. 1997) use a model tracing methodology.

\section{Approach and Contributions}

The first step in the approach we adopted was to unpack and interpret Vygotsky's writing about the ZPD. The concept as introduced lacked specificity about the type of assistance that should be offered to learners, how it should be quantified and how it should be provided and withdrawn. Therefore, in order to clarify the ZPD in a manner that would assist in its operationalization two additional concepts were introduced:

1. The Zone of Available Assistance (ZAA); and

2. The Zone of Proximal Adjustment (ZPA).

The ZAA describes the variety of resources available within a learner's world. These resources could potentially provide different qualities and quantities of assistance. The ZPA is created from a sub-set of the resources from the ZAA and should represent the resources that most accurately match a learner's needs. Within the resources of the ZAA, one very special resource is a More-Able Partner or Partners who will help the learner. The learner and More-Able Partner/s work together to select the optimal resources from the ZAA to create the learner's ZPA. This conceptualization of the ZAA and ZPA represents an interpretation of the ZPD. In order to operationalize the ZPD for implementation in the Ecolab software a further factor was identified: the assistance offered to a learner must be flexible and capable of being increased and decreased, the assistance must therefore be quantifiable. Within the Ecolab this quantification is done with respect to 5 levels of help and 3 levels of task differentiation. The levels used at each step are used by the software to calculate its beliefs about each learner's ZPA. A few years after our 1999 paper others also wrote about the use and relevance of the ZPD for the design of intelligent tutoring systems (Murray and Arroyo 2002). The ZAA and ZPA are described more fully in the original paper, and also in Luckin (1998).

The metaphor underlying the presentation of the Ecolab to the child is that of an Ecology Laboratory. The Ecolab is an environment into which the child can place different organisms and with which she can explore the relationships that exist between them. The overall motivation that is presented to her is that she should explore which sorts of organism can live together and form a food web. Learners can use the menu commands to specify actions with the organisms they have placed in their Ecolab. For example, the child can specify that a sparrowhawk will eat a thrush. If the action specified by the child is possible it will occur and the changes can be observed. If the action is not possible the child will be guided (in accordance with the system variation in use) towards a possible alteration so that the effects of the selected action can be 
observed. When learners interact with the Ecolab they do not need to deal with the full complexity of possible food web inter-relationships straight away.

The learning environment provided by the Ecolab can operate in 4 phases of relationship complexity. This means that not all the possible actions with the Ecolab are available all the time. In phase one, which is the simplest, the relationships that can be formed by the Ecolab objects are only those between two organisms: a food and a feeder in the eat or be eaten by relationship. The second phase of complexity allows the formation of food chains and thus relationships between more than two organisms. The third and fourth phases allow the formation of food webs and relationships between all the different members of the web. The system can switch between these four phases from the less to the more complex, or in reverse from the more to the less complex. The activities available to direct children's actions are consistent with the phase of complexity at which the Ecolab is currently operating.

A further variation in what children experienced with the Ecolab was that the Ecolab environment could be viewed in different ways, each of which emphasised a particular aspect of the animal and plant relationships which currently existed within the Ecolab: World view showed a picture of the organisms that were currently members of the Ecolab environment. Web view provided a diagrammatic representation of the organisms and the links that existed between them in a manner similar to the food web diagrams used in text books. Energy view illustrated each of the live organisms in terms of their current level of energy in a block graph. Figure 1 illustrates the original Ecolab interface. These different views expanded the ZAA for learners.

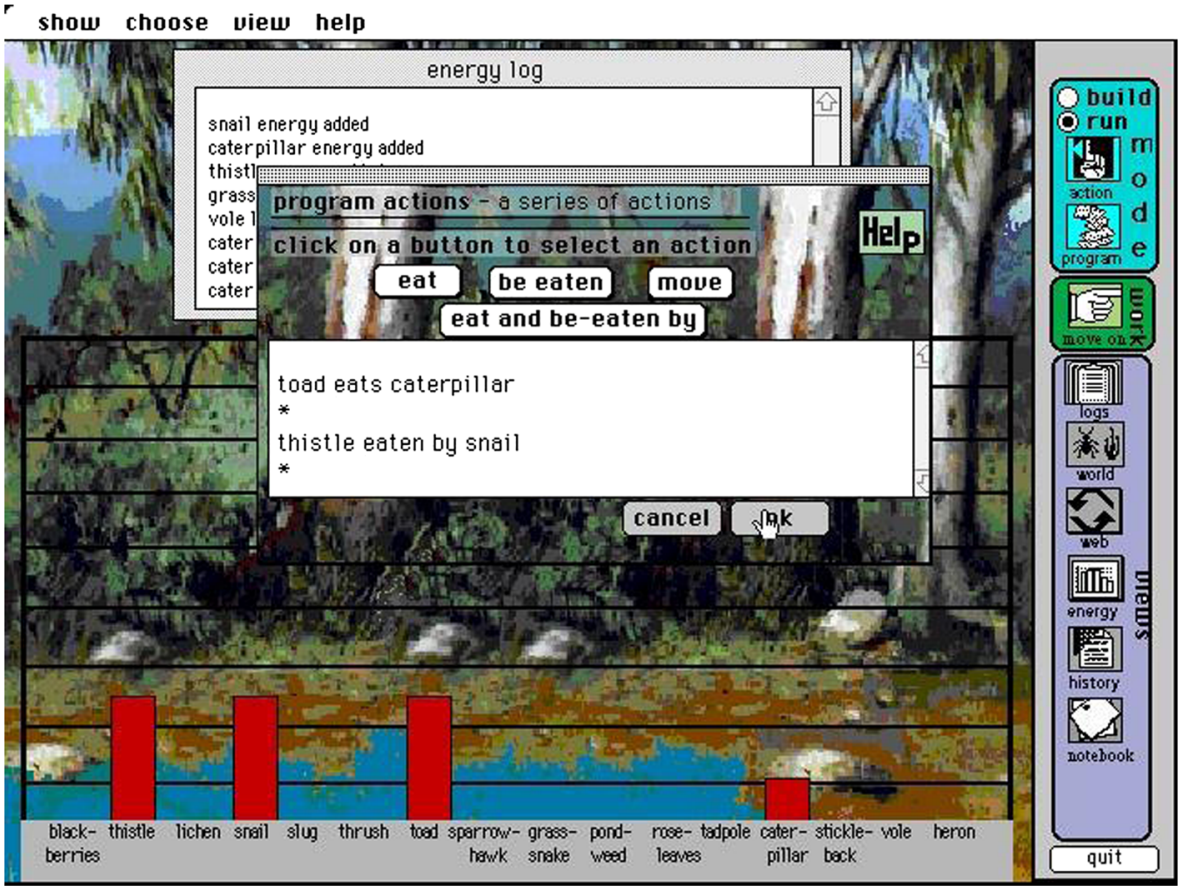

Fig. 1 The Ecolab interface in energy view 
The design and implementation of the Ecolab software was built around the concepts of the ZAA and ZPA. In the software the resources available to the learner (the ZAA) are: the animals and plants that could be placed in children's simulated worlds; the flexible complexity of the different phases of the simulation environment; the actions that can be completed; and the different views that children can use to look at their simulation. While switching views is not essential to any of the activities, it can provide additional help as each view offers a different form of information about the ecology system.

The underlying knowledge of food chains and webs used by the software was organized in a manner that reflected educational requirements about the concepts to be learnt and which ones might be particularly problematic. Knowledge about the problematic areas of the curriculum was taken from analysis completed by Griffiths and Grant (1985).

Three versions of the Ecolab software were developed in order to enable the comparative evaluation we reported: VIS (Vygotskian Instructional System, the full version of the software inspired by Vygotsky's ZPD); WIS (Woodsian Instructional system, a system that adopted a contingent approach to supporting the learner based upon the work of David Wood (Wood et al. 1976); and NIS (Notheory Instructional System, a system that offered no support other than that inherent in the simulated world environment). The More-Able Partner's role is played by the VIS and WIS versions of the software through the selection of different levels of help and different levels of Activity Differentiation between individual learners. Decisions about how to target the assistance offered by the VIS system's More-Able Partner are based upon a detailed, dynamic model of 'beliefs' about the learner's ability to solve problems. The learner model within VIS was an overlay of the curriculum knowledge structure. For each learner a model of this knowledge structure of rule and concept nodes is maintained. However, whereas in the domain knowledge structure an element of the curriculum is associated with each curriculum node (rule or terminology abstraction), in the learner model there were 2 values, referred to as tags associated with each node. The first value: the ability belief tag was the system's 'belief' about the child's independent ability with respect to this node. The second value: the collaborative support tag was a quantitative representation of the amount of collaborative support which the system needs to provide for the child in order to ensure her success with the equivalent node in the knowledge base. These tags allowed the modelling of the system's beliefs about which areas of the curriculum were outside the child's independent ability and the extent of the collaborative support required to bring each of these areas within her collaborative capability.

The learner model was dynamically updated after each action completed by children with the software. Changes to the model were based only upon the learner's interactions with the software and not on any self report or observational data. The decisions based upon this learner model helped to target the resources of the ZAA for a particular learner to form the interactions of their ZPA. In the WIS version of the system there was no sophisticated learner model, but rather a record of the learner's most recent action in terms of its success or failure. Decisions by the WIS system's More-Able Partner were based upon the contingency principle that if the learner's most recent action had been successful then less help would be offered, if the learner's most recent action had been unsuccessful then more help would be offered. In other words the help offered was 
contingent upon the learner's most recent success or failure. Both the VIS and WIS systems could be considered as attempting to provide assistance to learners in a manner that would support the creation of a ZPD. In neither system is the assistance offered presented through an agent. The difference between them was in the detail of the learner modeling that supports the decision making about how much help to offer learners. There was also a difference in the way that help was provided by each of these systems: In VIS the support the system deemed optimal was provided, whereas WIS suggested to learners the support that it deemed optimal, but left the selection of actual support used to the learner. This design decision for the WIS system was in line with Wood's approach to temporal contingency.

The evaluation of the Ecolab software reported in 1999 took place in a school classroom. It demonstrated that the software was suitable for the classroom context. Learners completed a pre and post test, through which we identified learning gains. We also recorded learners' interactions with the software, which enabled us to explore the relationships between different learner behaviours and learning gain. The findings from the evaluation indicated that offering learners a combination of challenging activities and appropriate support could improve test scores, which may indicate learning. The VIS version of the Ecolab produced the greatest average improvement in test scores, but was not the most successful system with learners of all abilities. The mean improvement amongst WIS users who were in the high ability group was greater than those for VIS and NIS. Likewise the mean learning gains for low ability NIS users were higher than those for WIS and VIS. When considering these findings one must bear in mind the small number of participants, nevertheless it is interesting to explore them further.

The findings prompt a range of questions. For example, one can wonder why lower ability learners do better with the system that had no scaffolding interventions. The answer may lie in the observation that these children limited themselves to a small part of the Ecolab and often repeated actions again and again, thus practicing and learning via rehearsal. The NIS version of the system allowed learners the freedom for such repetition, whereas the VIS system did not. Perhaps the VIS learner model was not sensitive enough to adapt to the less able learners and allow them to repeat actions many times? Perhaps the ZPA was not constructed accurately by VIS or WIS with respect to lower ability learners? Why did high ability learners learn more with the WIS version of the system? The WIS version of the system suggested what learners should do in terms of choosing task difficulty and choosing help level. Perhaps high ability learners preferred this approach, because it gave them more control than the VIS system? Questions like this led us later to adapt the design of the VIS system and to explore what elements of WIS and NIS it might be valuable to adopt in the next version of the Ecolab. Both the interpretation of the ZPD and the Ecolab software have been used for a rich vein of research in the years following upon their original introduction. These were the core contributions of the work we reported in 1999 which along with the pre and post tests used in the system evaluation facilitated subsequent development and deployment.

Returning to the underlying concepts of the ZAA and ZPA: the ZAA in VIS, WIS and NIS were identical except for the existence and nature of the More-Able Partner. In NIS there was no More-Able Partner and it was down to the learner to create their ZPA, whereas in VIS and WIS there was a More-Able Partner. In VIS and WIS the More- 
Able Partners operated on different principles and therefore worked with learners to create their ZPAs on a different basis.

\section{Practical Impact and Further Development}

The lines of work presented in this paper can be related to the ZPD model as follows: The original evaluation of the EcoLab explored the question of how the software in its different versions could determine the level of help and task differentiation the learner needs, which is a fundamental part of the ZPA. The later work with Ecolab II exploring metacognitive, motivational and goal oriented scaffolding investigated how the resources within the ZPA of a learner could be expanded.

One area of the work we originally reported has not been expanded on by us or by others as far as we know. This was the element of the domain knowledge representation within the Ecolab that was informed by Vygotsky's view of concepts, as either scientific or everyday (Vygotsky 1978, 1986). Attention was paid to designing the Ecolab knowledge representation as a hierarchical system. The organisms were classified into a taxonomic structure and the terminology describing this structure ranged from language with which children would probably be familiar, such as "snail" and "grass", to language that was less familiar, such as "consumer" and "producer". In the original Ecolab the activities and actions could be completed using less or more familiar language, although few children experienced the less familiar language versions of the activities, as they did not spend long enough with the system for it switch this language in.

\section{The Ecolab II Studies: Expanding the Learner's ZPA}

In order to explore how the Ecolab might be further developed to better support all learners we looked to keep the ZAA as originally designed and to re-design the MoreAble Partner. In particular we were keen to maintain the sophistication of the VIS learner model, but to make the system more sensitive to less able learners and to use the way that WIS suggested the type of support that learners should adopt, rather than just offering it to them. This had worked particularly well with more able learners. We therefore investigated how learners might themselves be better at selecting appropriate challenges and help. We developed the Ecolab II software which aimed to provide metacognitive support to help learners improve their help-seeking and task selection skills and, through this, their performance in learning about food chains and webs. Ecolab II was designed to combine aspects of the original VIS and WIS system variations of the Ecolab. It offered different qualities and quantities of prompts to try to get children to consider what they should do next: be it selecting an activity or selecting how much help to ask for. For example, the system would suggest to the student: "Why not ask for more help?" if the student was failing to complete activities and not requesting help. In order for the Ecolab II software to be able to offer this type of assistance, additions were made to the learner model and three levels of metacognitive help were added to Ecolab's help repertoire. A third value was added to each of the rule nodes in the learner model structure we originally described in 1999. This value was used to represent how aware the children were of their own learning 
needs and it was based on a combination of their use of the metacognitive hints and their performance with the Ecolab activities. This value was used to decide upon the level of the next metacognitive prompt offered to the learner and to make recommendations to the learner about how much domain level help to request. Other systems that model learners' help-seeking behaviour include the approach of Aleven et al. (2004), who developed a cognitive tutor to support help-seeking. Their approach to scaffolding involves focusing on the learner and providing fadable scaffolding advice. The difference in their approach compared to that adopted in the Ecolab II can be seen in their development of an ideal help-seeking model to support the system in detecting when the student deviates from the ideal, so that appropriate feedback can be provided. The broader topic of metacognition and learning has increased in popularity and this is reflected well in Azevedo and Aleven (2013), which provides much useful information for those wishing to explore the scaffolding of metacognition.

The available assistance within the original Ecolab software was through the software scaffolding techniques, that is, the Ecolab ZAA, and could be targeted for a particular learner to form the interactions of their ZPA. These were partly in the control of the learner, and partly in the control of the software depending upon the version in use. The learner could decide upon the animals and plants to be added to their simulation, the actions they wanted to complete with those animals and plants, and the view they chose to look at their simulation. They could also select the initial activity they wanted to complete. This meant that children could select an activity that required them to use the most complex phase of simulation right at the start, or they could pick an activity that took them to the simplest phase. After this initial selection, the VIS system would then take over decisions about how the activity and phase might be changed in the light of the learner's performance with the activity they first selected. Obviously, the manner in which the learner could access the resources within the software was constrained by the way in which the software was written, in terms of the underlying knowledge representation, the learner model and the interface.

The resources that make up the ZAA of the Ecolab II software were very similar to those found in the original Ecolab software, with the addition of metacognitive help. The learner model that specified the way that the Ecolab II More-Able Partner scaffolded learners contained additional information about learners' use of this metacognitive help. This scaffolding was offered through the provision of suggestions made to the learner about how much help they should use and what level of task difficulty they should attempt. In Ecolab II there was a move towards decreasing the control taken by the system for the assistance offered to the learner in comparison to VIS and increasing the information provided to learners about the ZAA to support their own decisions about the assistance they needed to use in the construction of their ZPA. A new interface element was introduced to help learners reflect upon their performance and make decisions about the assistance they should use. It provided learner with a More-Able Partner of the curriculum overlaid with information about how much assistance learners had used to complete activities at each point in the curriculum (see Fig. 2).

An evaluation of Ecolab II was conducted in which separate groups of learners used the software either with or without the metacognitive scaffolding (Luckin and Hammerton 2002). The learners using the metacognitive scaffolding version of Ecolab II in this evaluation demonstrated some interesting consistencies with the 


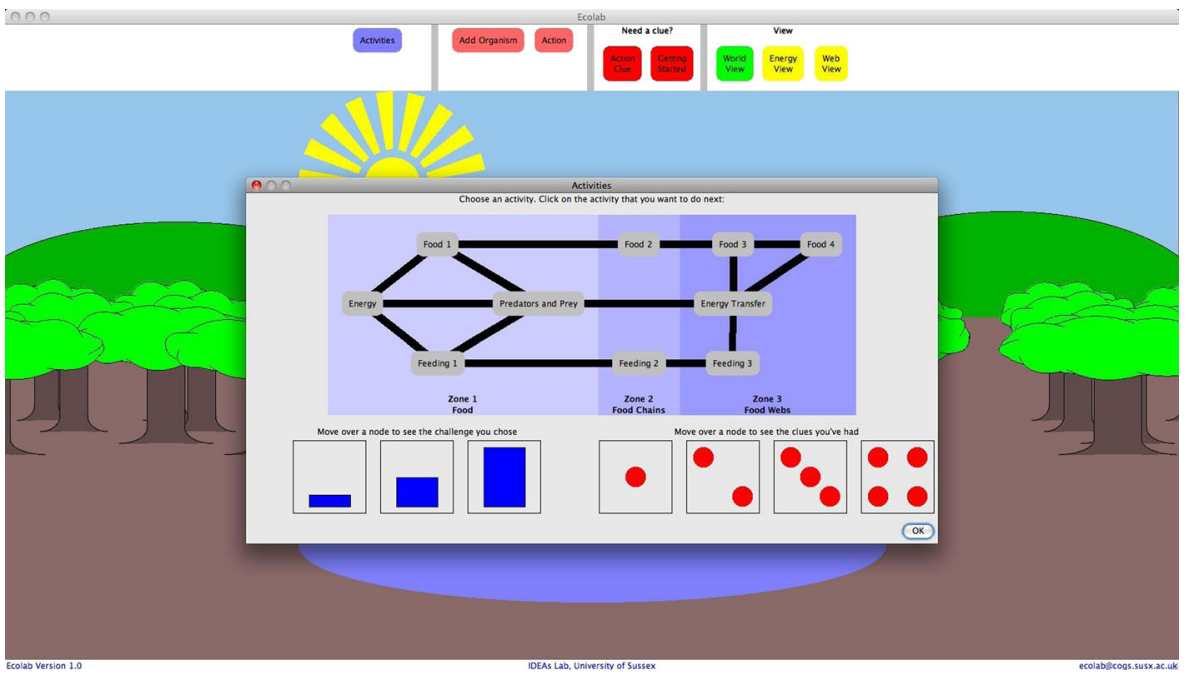

Fig. 2 The Ecolab II interface with curriculum map

original Ecolab evaluation. In both evaluations learners who tackled more than one phase of Ecolab simulation complexity performed well at post-test. An odds-ratio analysis illustrated the consistency of these results between the original Ecolab and Ecolab II. Children who both interacted with different phases of simulation complexity and completed an above average number of actions were 11.4 times more likely to be amongst the learners achieving above average learning gains with Ecolab II, and 12.4 times more likely with the original Ecolab. In other words extending learners so that they interact with more complex concepts is consistent with learning. Another consistency between the Ecolab and Ecolab II was seen in the high percentage of children with above average learning gains who used a high level of help (level three domain help or above; level two metacognitive help or above) and an above average amount of system assistance. The students who gained most when using Ecolab or Ecolab II were those who were extended to work at a greater level of complexity and supported through help interventions. This feature of extension and support is consistent with the concept of the ZPD. Ecolab II encouraged this learner profile through the way that the More-Able Partner in the system worked with learners to create an appropriate ZPA from all the assistance available within the ZAA. An interesting feature of the results from two empirical studies was that this time less able learners made the greatest learning gains. This finding suggests that less able learners respond well to interactive systems that offer appropriately challenging tasks and effective support to ensure that success is achieved.

\section{Further Studies with Variants of Ecolab II}

Further studies adapting and using the Ecolab II software have been conducted. These demonstrate the usefulness of the Ecolab II software for exploring a range of issues, and are relevant to understanding more about affect and self-regulation. Within the AIED community there was a growing body of work about the impact of motivation and affect on learning with technology and we decided to explore how the ZPA within the 
Ecolab might be expanded to encompass such issues. Each of the studies adds an extra resource to the ZAA of the Ecolab that present ever increasing challenges for MoreAble Partners to work effectively with learners to create their ZPA. Rebolledo-Mendez developed a system called M-Ecolab that monitored learners' levels of effort, independence and confidence to build a model of learners' motivation. Assistance consisted of providing levels of motivational feedback by suggesting to, but not directing, the learner when to ask for more challenging tasks, when to put in more effort or when to select more or less help. M-Ecolab built on each previous Ecolab system and maintained the original domain level assistance mechanisms. The results of a pilot study investigating the effect of motivational scaffolding in M-Ecolab showed that learners with greater learning gains had requested a higher level of help (RebolledoMendez et al. 2005). The results of a second evaluation showed a significant difference in learning gains between different ability groups and once again illustrated the relationship between learning gain and the use of a higher level of system help and taking on more challenging tasks (Rebolledo-Mendez et al. 2005). This work was continued through a comparative analysis of the Ecolab and M-Ecolab software conducted in the Phillipines and demonstrated that both systems were able to sustain some positive affective dynamics; flow was persistent in Ecolab (significant) and delight was persistent in M-Ecolab. However, neither system was able to disrupt the persistence of boredom and frustration in students over time (Rodrigo et al. 2008).

Martinez-Miron (2007) explored the deployment of different strategies for offering assistance according to different goal orientation styles (Eison 1979). Two new versions of the Ecolab II software were implemented. One version included system feedback that emphasized a mastery goal orientation (moEcolab), the other a performance goal orientation (poEcolab) (Martinez-Miron 2007). In the case of mastery goal orientation, the system provided learners with "self-referenced assessment through information regarding their previous scores in each activity, as well as the levels of challenge and help that had been selected within that activity. The information about their performance was shown in two fields: a) number of correct actions, and b) number of incorrect actions." In the case of performance goal orientation, the system provided learners with "norm-referenced assessment via two buttons: See my score and See my classmates' scores. The former shows a record of how many correct actions the student has made so far" (Martinez-Miron 2007, page 48).

An empirical evaluation study with learners aged between 9 and 11 years found evidence that performance goal oriented feedback provided by the system affected the way children interacted and learned from the system, in particular there was a trend in the data that suggested that correctly matching the goal orientation of the child to the goal orientation provided by the system improved learning gains.

The issue of goal orientation was explored further using Ecolab II in a study that investigated the extent to which mastery and performance goals influence learners' help-seeking behaviours when using Ecolab II (Harris et al. 2009). There were two options for seeking help while using Ecolab II: clues or views. A clue was presented automatically after an error is made. Children could then choose the type of clue they want; clues ranged from level one (least specific) to level four (most specific). As well as receiving clues children could also move freely between the Ecolab views. For the specific task given to the children in this study, the Web view was the most effective way of seeing different food chains and the Energy view was the least useful for this 
task. Analysis of the activity logs resulting from an empirical study indicated that there was no difference between mastery and performance oriented learners in the number of times they chose lower level clues. However, while highly variable, performanceoriented children tended to select clues at the higher end of the scale more frequently than their mastery-oriented counterparts. Performance-oriented children were also significantly more likely to move on to another problem if the clue they had selected had not helped them immediately. Mastery-oriented children clicked between World and Web view more often and made significantly more use of the Web view than the performance-oriented children. Although not significant, it is interesting to note that performance oriented children made more use of the Energy view, which was the least helpful. The differences we observed in this study between mastery- and performanceoriented children's help-seeking behaviour using Ecolab II highlighted the importance of considering this motivational dimension when supporting children's learning. The findings also highlight potential future work concerning the development of scaffolding that is sensitive to a learner's goal orientation and adjusts the advice that is offered accordingly.

\section{Lessons Learned}

The lessons learned fall into two categories. First we look at the more specific lessons drawn from the work on Ecolab. Second we discuss the wider implications of contexts that cover more than a single piece of software such as Ecolab.

\section{Limitations of the Ecolab Software}

In the original Ecolab the activities were part of the software and were linked to the fixed curriculum of domain knowledge. This directed the manner in which the simulated environment of the Ecolab could be explored. In subsequent versions of the Ecolab the activities were presented in a booklet that was separate from the Ecolab software environment. The Ecolab software directed the learner to the appropriate page of the booklet once an area of the curriculum had been selected. This latter approach had the potential to be more flexible in terms of the activities available for learners to complete, because it would allow teachers to easily author their own activities to be used with the Ecolab environment. We hoped that teachers might want to author these activities for learners, but in reality they did not and the same booklet of activities was used in all subsequent studies with the Ecolab and leaves open the possibility for teachers to introduce new activities should they so wish. The original Ecolab software enabled children to explore populations of organisms as well as individual organisms. The feature was part of the most complex phase of the miniworld simulation and was rarely used by any learner, perhaps because of the limited length of time that learners used the Ecolab. Populations were not implemented in Ecolab II, but they could be added and learners could be encouraged to use the software for a longer period of time.

A related limitation was that of the curriculum itself, which was limited by the software's knowledge representation. The effort of developing the system was significant, but the area of the curriculum it covered was small. This was acceptable for a research tool, but would be a serious limitation for the development of a commercial 
system. Ways of dealing with this challenge include exploring the extent to which the meta level scaffolding in Ecolab II could be generated in a domain independent manner.

A further limitation of the Ecolab software was that its design did not encompass people acting in the role of a More-Able Partner. It was not designed for use by a teacher and a learner, but for a single learner to use the software independently. There is however nothing to preclude teachers and parents from getting involved and asking learners about their activities with the Ecolab.

The Ecolab software offered learners a limited world of animals and plants with activities to be completed. It attempted to help learners to use this world to increase their understanding of food chains and webs. This was the case for most Intelligent Tutoring Systems at that time. The proliferation of internet access to schools and the rapid development of mobile smart technology means that there are potentially vast resources available and the role of a closed system such as the Ecolab is dated. This does not mean that we cannot learn from the studies completed with the Ecolab, but it does mean we need to update the ways in which we implement this learning. This is very much at the heart of the work on the Ecology of Resources that has grown out of the Ecolab work (see next section).

A possible implication of Vygotsky's ZPD notion is that the effect of the actions and help of the more able partner is to improve the learner's rate of learning. Lack of help or poorly focused help would not usually help children to succeed, and so its the success following strenuous mental effort and the reflective internalization of that collaborative success which drives learning. This suggests that an alternative model of evaluation would not just compare differences in pre/post scores as has been done, but also compare time on task to reach specific learning criteria as well as look at degrees of engagement during learning.

\section{The ZAA and the ZPA in a Wider Context}

The concepts of the ZAA and the ZPA have been further developed into the Ecology of Resources model of context (Luckin 2010). This work moves beyond the confines of a piece of software and grapples with the complex issue of how a learner's wider context can be described in a manner that permits it to be taken into account in the way that educational technology is designed and used. The Ecology of Resources is a specification and a method for modelling a learner's context. It is grounded on a particular definition of context:

A learner is not exposed to multiple contexts, but rather has a single context that is their lived experience of the world; a 'phenomenological gestalt' (Manovich 2006) that reflects their interactions with multiple people, artefacts and environments. The partial descriptions of the world that are offered to a learner through these resources act as the hooks for interactions in which action and meaning are built. In this sense, meaning is distributed amongst these resources. However, it is the manner in which the learner at the centre of their context internalizes their interactions that is the core activity of importance.

Luckin 2010 Page 17

The resources with which learners interact make up their ZAA and as in the Ecolab the role of the More-Able Partner is to work with learners to select the optimal 
resources from a learner's ZAA. However in the Ecology of Resources the ZAA extends beyond a single piece of software to describe learners' broader contexts, including their peers, home environment and wider school resources beyond their classroom. Associated with the Ecology of Resources model is a design framework with a three-phase process for working with educators to develop context sensitive technologies and technology applications.

\section{Open Issues and Future Needs}

The increased attention that is currently being given to what are referred to as $21 \mathrm{st}$ Century skills confirms the perceived need for learners to develop good metacognitive skills. We have made progress in understanding how these skills can be scaffolded through our evaluations of Ecolab II. Specifically, in Ecolab II we have shown how three levels of metacognitive scaffolding can be used in conjunction with four levels of domain level scaffolding to help learners select appropriate support to aid their completion of activities. However, as already identified the software only deals with a small part of the science curriculum and the metacognitive skills that are supported are limited to help seeking behavior and challenge selection. There is much work still to be done in understanding and developing metacognitive scaffolding. This is also true for the issue of software scaffolding more generally. The studies with the Ecolab explored the design of scaffolding with respect to an increasing number of parameters that included not only metacognition, but motivation and goal orientation too. The empirical work has demonstrated some of the possibilities, but there remain significant questions. For example, in the case of learners' goal orientation should learners be scaffolded to behave in a mastery manner, or should they be scaffolded to support their naturally prevailing goal orientation? If a future version of Ecolab were to be developed that offered scaffolding for metacognition, motivation and goal orientation, how might any conflicts between these approaches be resolved? The Ecolab II interface illustrated in Fig. 2 opened up aspects of the learner model for the learner, might further opening up and visualization of the learner model further scaffold learning?

Vygotsky's work was the original impetus for the research we reported in 1999 and it is still a driving force for subsequent and current work. His research was conducted in post-revolutionary Russia in very different circumstances to those in place today. His work is however still extremely relevant. The ZPD was introduced as a way of challenging the testing methods being used in schools at that time. These methods only evaluated what the learner already understood and took no account of things that the learner could achieve with some assistance from a more able other. Much of the educational world remains committed to testing regimes that only evaluate an individual's independent understanding. In contrast the world of work increasingly demands individuals who can work and develop as part of a team. The concept of the ZPD has lost none of its usefulness and remains in need of further interpretation and development.

The advent of mass educational technology uptake has resulted in large data sets arising from learners' interactions with the technology. This has produced the new field of Learning Analytics that explores what these large data sets can tell us about learners' performance and behaviour. The methods used to track and model learner behavior in 
the Ecolab and Ecolab II studies were seen to be effective at supporting the system as a More-Able Partner for learners. These same methods may now be appropriate for use on these large data sets to track the development in learners' understanding. For example, if sources of assistance can be identified in learners' interactions in these large data sets, then perhaps learners' use of these forms of assistance can be tracked and used to interpret learner understanding in a manner similar to that used in Ecolab's learner model.

The concepts of the ZAA and ZPA have been useful in much subsequent work since the original 1999 article, both through the range of studies conducted with Ecolab II and work with the Ecology of Resources. The Ecolab II studies explored an ever increasing range of potential resources for the software's ZAA including motivational resources and goal orientation resources. The Ecology of Resources extends the ZAA and ZPA concepts beyond learners' interactions with the Ecolab to their learning context more generally. This encompasses more of learners' lives and recognizes that the range of resources available to learners has increased over the years. Technology developments mean learners are rarely offline and can therefore almost always access information resources and people to help them with their learning. However, this increased availability does not mean that learners are necessarily good at pulling together the most appropriate resources to meet their needs. There is an increasingly important role for a More-Able Partner, whether in the form of software, people or some combination of the two.

\section{References}

Aleven, V., McLaren, B. M., Roll, I. \& Koedinger, K. R. (2004) Toward tutoring help seeking — Applying cognitive modeling to meta-cognitive skills. Lecture Notes in Computer Science 3220 (pp. 227-39). Berlin: Springer-Verlag.

Azevedo, R., \& Aleven, V. (Eds.) (2013). International handbook of metacognition and learning technologies. New York: Springer.

Azevedo, R., Witherspoon, A., Chauncey, A., Burkett, C., \& Fike, A. (2009). MetaTutor: A MetaCognitive tool for enhancing self-regulated learning. In R. Pirrone, R. Azevedo, \& G. Biswas (Eds.), Proceedings of the AAAI Fall Symposium on Cognitive and Metacognitive Educational Systems (pp. 14-19). Menlo Park: Association for the Advancement of Artificial Intelligence (AAAI) Press.

Dede, C. Grotzer, T. A., Kamarainen, A., Metcalf, S, \& Tutwiler, M. S. (2012). EcoMOBILE: blending virtual and augmented realities for learning ecosystems science and complex causality. Journal of Immersive Education. http://JiED.org/1/1/2.

Eison, J.A. (1979). The development and validation of a scale to assess different student orientations towards grades and learning. Unpublished doctoral dissertation, University of Tennessee, Knoxville.

Griffiths, A. K., \& Grant, A. C. (1985). High school students' understanding of food webs. Journal of Research in Science Teaching, 22(5), 421-436.

Harris, A., Bonnett, V., Luckin, R., Yuill, N., \& Avramides, K. (2009). Scaffolding effective help-seeking behaviour in mastery and performance oriented learners. In V. Dimitrova, R. Mizogucji, B. du Boulay, \& A. Graesser (Eds.), Artificial intelligence in education (pp. 425-432). Amsterdam: IOS Press.

Koedinger, K. R., Anderson, J. R., Hadley, W. H., \& Mark, M. A. (1997). Intelligent tutoring goes to school in the big city. International Journal of Artificial Intelligence in Education, 8(1), 30-43.

Luckin, R. (1998). 'Ecolab': Explorations in the zone of proximal development. Unpublished D.Phil. Thesis, University of Sussex.

Luckin, R. (2010) Re-designing learning contexts: technology-rich, learner-centred ecologies, Routledge http://www.routledge.com/books/details/9780415554428/.

Luckin, R., \& du Boulay, B. (1999). Designing a zone of proximal adjustment. International Journal of Artificial Intelligence in Education, 10(2), 198-220. 
Luckin, R., \& Hammerton, L. (2002). Getting to know me: Helping learners understand their own learning needs through metacognitive scaffolding. In S. A. Cerri, G. Gouardères, \& F. Paraguaçu (Eds.), Lecture notes in computer science (vol. 2363, pp. 759-771). Berlin: Springer Verlag.

Manovich, L. (2006). The poetics of augmented space. Visual Communication, 5(2), 219-240.

Martinez-Miron, E. (2007) Goal orientation in tutoring systems. Unpublished D.Phil. Thesis. University of Sussex.

Murray, T., \& Arroyo, I. (2002). Toward measuring and maintaining the zone of proximal development in adaptive instructional systems. In Intelligent Tutoring Systems (pp. 749-758). Springer Berlin Heidelberg.

Rebolledo-Mendez, G., du Boulay, B., \& Luckin, R. (2005). 'Be bold and take a challenge': Could motivational strategies improve help-seeking? In C.-K. Looi et al. (Eds.), Frontiers in artificial intelligence and applications (pp. 459-466). Amsterdam: IOS Press.

Rodrigo, Ma Mercedes T., et al. (2008) The effects of motivational modeling on affect in an intelligent tutoring system. Proceedings of the 16th International Conference on Computers in Education (pp. 57-64). Taiwan: ICCE2008.

Vygotsky, L. S. (1978). Mind in society: The development of higher psychological processes. Trans. Cole, M., John-Steiner, V., Scribner, S., \& Souberman E. Cambridge: Harvard University Press.

Vygotsky, L. S. (1986). Thought and language. Cambridge: MIT Press.

Wood, H. A., \& Wood, D. (1999). Help seeking, learning and contingent tutoring. Computers \& Education, 33(2-3), 153-169.

Wood, D. J., Bruner, J. S., \& Ross, G. (1976). The role of tutoring in problem solving. Journal of Child Psychology and Psychiatry, 17(2), 89-100. 